\title{
Psychological Well-Being and Brokerage in Friendship Networks of Young Swedes
}

\author{
Gerald Mollenhorst • Christofer Edling $\cdot$ Jens Rydgren
}

Accepted: 9 September 2014/Published online: 20 September 2014

(C) Springer Science+Business Media Dordrecht 2014

\begin{abstract}
All ethnic groups have norms and values according to which one is expected to behave. Immigrants in particular have personal networks that simultaneously consist of coethnics and friends of a different ethnic background. As a consequence, they may be accustomed to the behavior, norms, and values of their own ethnic group, and also be expected to behave according to those of another ethnic group. This may either lead to egogratification and the strengthening and enrichment of their personality, or to feelings of stress and non-acceptance if they cannot behave fully in accordance with the expectations of their friends. This study addresses the association between interethnic open triads in networks (i.e., brokerage) and individual psychological well-being. That is, we examine whether having intra-ethnic and interethnic relationships with friends who are not also friends with each other, is either positively or negatively associated with psychological well-being. Using (network) data from a large sample $(\mathrm{N}=2,942$; age $=19)$ of native Swedes and first- and second-generation immigrants from former Yugoslavia and Iran (all born in 1990 and currently living in Sweden), we show that interethnic brokerage is negatively associated with psychological well-being, which implies that the different norms, values and corresponding behaviors that prevail in different ethnic groups to which the ethnic broker is connected may result in internal and external conflicts, to feelings that one is not fully accepted by any of these groups, and ultimately to a lower level of psychological well-being.
\end{abstract}

Keywords Interethnic relationships - Brokerage - Psychological well-being - Triads · Friendships $\cdot$ Personal networks

G. Mollenhorst · J. Rydgren

Department of Sociology, Stockholm University, Stockholm, Sweden

G. Mollenhorst (凹)

Department of Sociology/ICS, Utrecht University, PO Box 80.140, 3508 TC Utrecht, The Netherlands e-mail: g.w.mollenhorst@uu.nl

C. Edling

Department of Sociology, Lund University, Lund, Sweden 


\section{Introduction}

In this paper, we study how psychological well-being relates to brokerage positions in friendship networks, thereby specifically addressing brokerage between native and nonnative friends of young natives and immigrants in Sweden.

An established finding from earlier research is that people's psychological or subjective well-being is associated with having (or not having) personal contacts, more specifically, with the availability of supportive social relationships (e.g., Cohen and Wills 1985; Pierce et al. 1996). While negative relationships almost inevitably cause higher levels of stress and lower levels of well-being (Finch et al. 1989; Rook 1984), having positive relationships may not in itself always lead to comfortable feelings as well. Having positive relationships (such as friendships) with people from different social categories can lead to psychological stress and social instability if this implies that one faces varying and sometimes even conflicting role obligations (Goode 1960; Krackhardt 1999; Pescosolido and Rubin 2000; Sieber 1974). An individual can meticulously separate these different parts of his network - and thus occupy a brokerage position-but being part of different networks with different norms and values can be rather stressful and lead to lower levels of psychological well-being (Krackhardt 1999; Pescosolido and Rubin 2000; cf. Goode 1960; Sieber 1974).

We examine the association between the occurrence of brokerage positions in personal networks and psychological well-being, specifically focusing on what we call 'ethnic brokerage' between natives and non-natives in friendship networks of young native Swedes and immigrants from former Yugoslavia and Iran who live in Sweden. Ethnic groups are examples of social categories that often have varying norms and values according to which one is expected to behave. For immigrants, having interethnic friendships (which are predominantly friendships with native Swedes) may already increase stress, but we hypothesize this is especially the case if the immigrant is in an ethnic brokerage position, i.e., if she or he has friends of different ethnic backgrounds who are not mutual friends. In these circumstances, they may feel pressure to behave according to the norms and values of both friends. That is, they may feel pressure to behave according to the norms and values of her/his own ethnic group, and to the norms and values of the other ethnic group (predominantly natives). We therefore examine how ethnic brokerage positions are associated with individual psychological well-being, over and above the effect of merely being in brokerage positions and of merely having a multi-ethnic friendship network and while taking into account basic socio-demographic characteristics and one's self-rated physical health. In contrast to earlier studies, which addressed consequences of interethnic relationships for immigrants only, ${ }^{1}$ we examine the association between ethnic brokerage and psychological well-being for both native Swedes and for immigrants from Iran and former Yugoslavia.

\section{Background}

Our research question requires the integration of theoretical and empirical insights from three different strands of literature. First, there is ample research on the ethnic composition of personal networks (e.g., De Miguel Luken and Tranmer 2010; Fong and Isajiw 2000;

\footnotetext{
${ }^{1}$ By focusing solely on the networks of immigrants, most of these studies neglected the consequences of interethnic relationships for the native population. For an exception, see Martinovic (2013).
} 
Kalmijn 1998; Kao and Joyner 2004; Martinovic et al. 2009; Martinovic 2013; Vervoort and Dagevos 2011) and on the consequences of intra- and interethnic relationships for individual life chances. For example, having interethnic relationships is positively associated with destination-language proficiency in immigrants (Chiswick and Miller 1996) and with a higher likelihood of employment and higher occupational status (Kanas and Van Tubergen 2009).

A second relevant strand of literature focused on the consequences of network brokerage positions for individual well-being and life chances. These studies predominantly addressed the positive effects of brokerage positions (also called structural holes) on career outcomes. For example, having innovative ideas and upward mobility within the company were found to be positively affected by large information networks that are full of structural holes (Burt 1992; Podolny and Baron 1997; see also Bian 1997; Granovetter 1974).

And a third strand of literature addressed the psychological well-being of immigrants. Research findings in this respect do not show a general pattern of different levels of psychological well-being among immigrants as opposed to natives, but some empirical studies show that immigrants' psychological well-being varies, among other things between ethnic groups and with the immigrant's length of stay in the host country, strength of ethnic identity, level of assimilation, and perceived level of discrimination (e.g., Bankston and Zhou 2002; Harker 2001; Greenman and Xie 2008; Liebkind and JasinskajaLahti 2000; Phinney et al. 2001; Verkuyten and Nekuee 1998).

We combine these three strands of research, because we argue and expect that connecting ethnic groups that would otherwise be unconnected-because there are no other relationships between members of both ethnic groups-has additional consequences over and above the effects of having interethnic personal relationships. These additional consequences may occur to the individual who is in the brokerage position, to the ethnic group to which he/she belongs, and to the broader society. In addition, we argue that the consequences of network brokerage are especially important if brokerage occurs between two distinct social groups, such as ethnic groups, that are both insulated and proximate (Stovel and Shaw 2012). We therefore examine the consequences of ethnic brokerage for the psychological well-being of young natives and (first and second generation) immigrants from former Yugoslavia and Iran who are currently living in Sweden.

In Sect. 3, we (a) discuss the concept of 'brokerage' and how we define ethnic brokerage in this study, and (b) summarize previous findings on the occurrence of ethnic brokerage in friendship networks. In Sect. 4, we discuss and formulate hypotheses on the association between ethnic brokerage and psychological well-being, based on previous theoretical and empirical studies. To test our hypotheses, we use (network) data on 1,382 native Swedes, 928 first and second generation immigrants from former Yugoslavia, and 632 first- and second-generation immigrants from Iran, who are all born in 1990 and currently live in Sweden. These data are described in Sect. 5. We present and interpret the results in Sect. 6, after which we draw conclusions and discuss their potential implications in Sect. 7.

\section{Ethnic Brokerage in Friendship Networks of Young Natives and Immigrants in Sweden}

\subsection{What is Ethnic Brokerage?}

Previous studies on brokerage in networks employed a variety of definitions and measurements of brokerage. All of these definitions commonly state that a broker (a) bridges a 
gap in social structure and (b) may help goods, information, opportunities, or knowledge flow across that gap (Stovel and Shaw 2012; cf. Burt 1992; Marsden 1982; Obstfeld 2005). In this study, we define brokerage as network triads in which the focal actor (i.e., the respondent) forms a link between two other actors (in our case, his/her friends) who are not directly linked to each other. ${ }^{2}$ Because we do not know whether or not the focal actor actually facilitates any direct or indirect transactions between his unconnected associates, this means that, in line with Burt (1992), we study brokerage positions (or 'brokerage opportunities') rather than actual brokerage.

As Stovel and Shaw (2012:140) clearly formulated, “... opportunities for brokerage arise when two or more distinct social entities are both insulated and proximate." Ethnic groups are examples of such distinct social entities: immigrants may live in the host country among other immigrants and natives - and in Scandinavia even more so than, for example, in the United States, where residential ethnic segregation is much more common (Brännström 2008; Edling and Rydgren 2012; Musterd 2005)—but they tend to have a disproportional number of co-ethnic friends. On top of that, we know from previous research that in Scandinavian countries, immigrants have the most ethnically diverse networks, consisting of co-ethnic friends, a relatively large proportion of native friends, and friends of a different ethnic background (e.g., Mollenhorst et al. 2012, 2013). This also implies that segregation in these countries is predominantly based on the (fuzzy) distinction Swedish versus non-Swedish (cf. Brännström 2008; Edling and Rydgren 2012; Musterd 2005).

Consequently, we examine the association between ethnic brokerage in friendship networks and individual psychological well-being, while defining ethnic brokerage as the occurrence of open multi-ethnic triads in friendship networks. We are especially interested in the consequences of open triads that consist of one co-ethnic friend and one friend of another ethnic background. And in the case of immigrants, we give special attention to cases in which this 'friend of another ethnic background' is a native Swede. Essentially, we distinguish four different ethnic configurations of brokerage relations that may occur in friendship networks. ${ }^{3}$ These four configurations are depicted in Fig. 1.

In each of the four figures in Fig. 1, the top actor represents the focal actor. The crucial difference between the four configurations is whether one's friends have the same ethnic background as the focal actor and/or whether these two friends are of the same ethnic background. First, coordinator brokerage represents the situation in which all three actors have the same ethnic background. In fact, coordinator brokerage is intra-ethnic brokerage, not interethnic brokerage. Second, cosmopolitan brokerage represents the situation in which both of one's friends have the same ethnic background, which is different from that of the focal actor. This is an interesting configuration if the focal actor is an immigrant and his/her two friends are both natives. In that case, the immigrant builds bridges to multiple groups (or networks) of native Swedes, which may result in access to varied sources of information, but not necessarily to exposure to different (cultural) norms and values. Third,

\footnotetext{
${ }^{2}$ Of course, brokerage is more likely in networks of less intimate relationships than in friendship networks. In terms of receiving non-redundant information, the advantages of occupying a brokerage position may also be more applicable in networks of less intimate relationships. However, regarding psychological well-being, we expect that effects of brokerage are more likely in networks of strong relationships, because people are more likely to behave according to the norms and values of their strong contacts than to those of their weaker contacts.

3 These four configurations are based on the five configurations of brokerage relations as presented in Gould and Fernandez (1989). For a more detailed description of these four configurations, see Mollenhorst et al. (2013).
} 


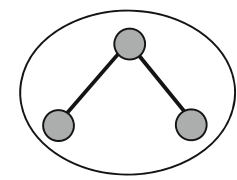

Coordinator

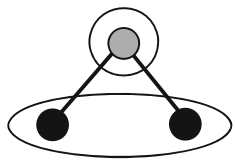

Cosmopolitan

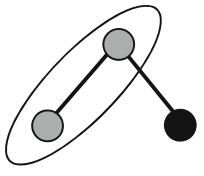

Gatekeeper/ Representative

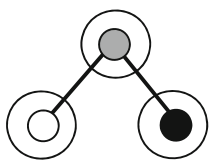

Liaison

Fig. 1 Four brokerage configurations

gatekeeper or representative brokerage represents the situation in which one of the focal actor's friends has the same ethnic background as the focal actor, while the other friend has a different ethnic background. This configuration includes the situations to which we pay special attention in this study: open triads that consist of one co-ethnic friend and one friend of another ethnic background. ${ }^{4}$ Fourth, liaison brokerage represents the situation in which all three actors have a different ethnic background. This implies that the focal actor herself or himself connects to multiple ethnic groups and also builds a bridge between both of these ethnic groups, without having prior allegiance to either of these two groups.

\subsection{Previous Findings on the Occurrence of Ethnic Brokerage}

In an earlier paper, we examined the occurrence of ethnic brokerage in friendship networks using the same data from a large sample of young native Swedes and young first and second generation immigrants from former Yugoslavia and Iran who are currently living in Sweden (Mollenhorst et al. 2013). We found that immigrants and natives have about an equal proportion of open triads (=brokerage opportunities) in their friendship networks (about $40 \%$ of all triads). However, because immigrants from former Yugoslavia and Iran have predominantly interethnic friendships (see Appendix 1), open triads in the networks of immigrants also predominantly consist of friends of another ethnic (often Swedish) background. This implies that, as compared to native Swedes, friendship triads of former Yugoslavians and Iranians are much more likely closed interethnic triads and-most importantly - also more likely open interethnic triads. ${ }^{5}$ In other words, intra-ethnic brokerage is the typical brokerage configuration for native Swedes and inter-ethnic brokerage is the typical brokerage configuration for immigrants. Furthermore, we found that, compared to men, triads in friendship networks of women are more often open triads, and that especially immigrant women are likely to be in an ethnic brokerage position.

\section{Theory and Hypotheses on Ethnic Brokerage and Psychological Well-Being}

While not explicitly using the term 'brokerage', Simmel (see, e.g., 1950, 1908[1950], 1922[1955]) had already pointed at the consequences of being a member of different social

\footnotetext{
4 According to our data, in $84.1 \%$ of the cases of gatekeeper/representative brokerage among former Yugoslavians, one's friend is also from former Yugoslavia, while the other friend is a native Swede. In $82.8 \%$ of the cases of gatekeeper/representative brokerage among immigrants from Iran, one's friend is also from the Middle East, while the other friend is a native Swede.

5 Marginal effects, based on multinomial regression analyses, indicated that, compared to native Swedes, friendship triads of former Yugoslavians and Iranians are about $46 \%$ more likely to be closed interethnic triads and $28 \%$ more likely to be open interethnic triads (see Mollenhorst et al. 2013).
} 
groups, and he argued that it may provide unique opportunities, but also lead to a sense of anomie. In subsequent research, various scholars examined both the negative and the positive consequences of being a broker. Most studies, however, focused on one side, although research that only focuses on either the positive or on the negative consequences of brokerage cannot adequately test the theory (cf. Sieber 1974:568). In this section, we discuss theories and empirical research, and we formulate hypotheses about the (positive and/or negative) consequences of ethnic brokerage on psychological well-being.

Role theorists such as Goode (1960) have argued that having multiple relationships with diverse role partners is a source of psychological stress and social instability (Sieber 1974; cf. Marks 1977). Goode introduced the term 'role strain' to indicate the potential problems of performing multiple roles. If individuals face varying and sometimes even conflicting role obligations, conforming fully in one direction inhibits conformity in another direction. ${ }^{6}$ Merton addressed the problem of conflicting role obligations from a structural perspective: "It would seem that the basic source of disturbance in the role-set is the structural circumstance that any one occupying a particular status has role partners who are differently located in the social structure. As a result, these others have, in some measure, values and moral expectations differing from those held by the occupant of the status in question" (Merton 1957:370).

From this perspective, a multi-ethnic friendship network may imply having friends with different values and moral expectations. Behaving fully in accordance with the values and moral expectations of co-ethnic friends may then be in conflict with and consequently come at the cost of behaving in accordance with the values and moral expectations of another friend of a different ethnic background.

Some scholars have argued that being a member of multiple groups has negative consequences because they "become a source of internal and external conflicts by creating multiple pulls among the individual's values, norms, and sanctions. [...] In sum, the price individuals pay for modernism is a weaker personal and local safety net in which multiple groups pull the individual in different directions" (Pescosolido and Rubin 2000:57; cf. Krackhardt 1999). For immigrants, behaving fully in accordance with the expectations of their co-ethnic friends would then inhibit behavior in accordance with the expectations of their other friends, including natives, which may lead to stress, to feelings that one is not fully accepted by any of the ethnic groups, and ultimately to a lower level of psychological well-being.

This is especially likely to happen to ethnic brokers (over and above merely having a multi-ethnic network), because brokering between two ethnic groups means that two of the focal actors' contacts belong to a different ethnic group and are not mutually connected, which may indicate salient substantial differences between the norms, values, and corresponding behaviors between both ethnic groups. Based on this perspective, we hypothesize (Hyp 1): Ethnic brokerage in friendship networks is negatively associated with psychological well-being (over and above the general effects of having interethnic friendships and of brokerage itself).

By contrast, others have argued that being a member of multiple social groups may "strengthen the individual and reinforce the integration of his personality" (Simmel

\footnotetext{
${ }^{6}$ Sieber (1974:567) noted that role strain in fact comprises two (overlapping) problems: role overload and role conflict. Role overload is a matter of time: as role obligations increase, sooner or later one is forced to honor some roles at the expense of others. Role conflict is a matter of discrepant expectations: sometimes one is forced to choose between honoring the expectations of $\mathrm{A}$ or of $\mathrm{B}$, because compliance with the expectations of one will violate the expectations of the other.
} 
1922[1955]:141-42). And for this reason, e.g., Sieber (1974:568) and Thoits (1983) addressed the question of "whether multiplicity of roles actually creates more strain than gratification, or more potential for disturbance than potential for stability" (Sieber 1974:568). Thoits (1983:175) even reasoned that—because behavioral expectations govern role relationships, giving purpose, meaning, direction, and guidance to people's lives - the more identities held, the stronger one's sense of meaningful, guided existence, the more 'existential security' (cf. Hällsten et al. 2012). Similarly, Sieber (1974:576) proposed that performing multiple roles could also "produce a good deal of ego-gratification, namely, the sense of being appreciated or needed by diverse role partners." Applying this to interethnic relationships and brokerage would mean that being able to conform to different and perhaps even conflicting ethnicity-based role obligations may lead to ego-gratification and strengthening and enrichment of one's personality. Based on this perspective, we hypothesize (Hyp 2): Ethnic brokerage in friendship networks is positively associated with psychological well-being (over and above the general effects of having interethnic friendships and of brokerage itself).

\section{Data and Methods}

\subsection{The Sample}

We use data from a Swedish survey titled Social Capital and Labor Market Integration: A Cohort Study. For this survey, a sample of 5,836 individuals was selected for a telephone interview by Statistics Sweden between October 2009 and January 2010 (Edling and Rydgren 2010). This sample consists of three different groups of Swedes who were all born in 1990: (a) all individuals with at least one parent born in Iran, (b) $50 \%$ of all individuals with at least one parent born in former Yugoslavia, and (c) a random sample of 2,500 individuals whose parents were both born in Sweden. With an overall response rate of $51.6 \%$, the number of respondents for each of these groups was 928 Yugoslavs, 632 Iranians, and 1,382 native Swedes (response rates for these three groups were respectively 46.6, 47.1, and $55.3 \%$ ).

The reason for specifically selecting individuals of an Iranian or former Yugoslavian background was to avoid the often problematic category of 'immigrants', which is too heterogeneous for many research objectives. In addition, this sampling procedure avoids the problem of ending up with small numbers of respondents from specific countries of origin. Iran and former Yugoslavia are both major sources of migration to Sweden. Immigrants from Iran are primarily refugees and other humanitarian migrants. Former Yugoslavia has been the origin of extensive labor immigration and more recently also of refugees.

\subsection{Dependent Variable}

In this study we examine the consequences of ethnic brokerage for an individual's psychological well-being. The survey contains thirty-one questions on personality and noncognitive resources. These items together represent a number of well-known psychometric constructs, among which are a number of indicators for psychological well-being. Our measure for psychological well-being is based on the following ten indicators for psychological well-being: (1) I have energy to do things; (2) Generally I am happy; (3) I am usually pleased with who I am; (4) I am happy with how I look; (5) I have no worries; (6) I 
am often tense and nervous; (7) I often feel sad and down; (8) I often feel lonely; (9) I am often grumpy and irritated; (10) I easily get angry. Each of these variables was measured with a five-category Likert-scale response scheme: $1=$ strongly disagree; 2 = disagree; $3=$ neither agree nor disagree; $4=$ agree; $5=$ strongly agree. We recoded these items such that a higher score indicates greater well-being and then determined that these ten items together form a reliable scale (with a Cronbach's Alpha of .81). Finally, we defined the variable for psychological well-being as the mean score of these ten indicators.

\subsection{Independent Variables}

\subsubsection{Friendship Network Delineation}

Friendship networks were determined by the name generating question "Who are the five persons whom you meet and hang around with most often in your leisure time?" Next, name interpreting questions were asked with regard to alters' characteristics, characteristics of the relationship between ego and alter, and the extent to which alters mutually know each other. Answers to these name interpreting questions were used to indicate ethnic brokerage and relevant alter or network characteristics.

\subsubsection{Ethnic Brokerage}

Ethnic brokerage is based on variables regarding the ethnic background of the respondent's friends, and the extent to which one's friends mutually know each other. With regard to ethnic background, all respondents were asked about the ethnic background of their friends. For each friend, we first asked whether he/she was born in Sweden. If the answer was negative, we asked for the specific country in which he/she was born. Because this research specifically focuses on whether relationships between respondents and their friends are intra- or interethnic, and whether potential relationships between the respondent's friends are intra- or interethnic, it is important that the measure that is used for the ethnic background of the respondent (or focal actor) is as similar as possible to the measure that is used for the ethnic background of their friends. As mentioned in the previous section, this sample consists of three groups with different ethnic backgrounds: a) Iranian immigrants with at least one parent born in Iran, b) Yugoslavian immigrants with at least one parent born in former Yugoslavia, and c) native Swedes whose parents were both born in Sweden. We therefore first recoded the variable for the ethnic background of one's friend by placing Bosnia, Croatia, Kosovo, Macedonia, Montenegro, Serbia, and Slovenia into one category labeled Former Yugoslavia, and by placing Arabic Country, Armenia, Assyria, Azerbaijan, Iraq, Iran, Syria, and Turkey into one category labeled Middle East.

Next, all respondents with two or more alters were asked whether or not these friends mutually know each other (with answer categories 'yes' and 'no'), and subsequently how well these network members know each other (with answer categories 'not very well', 'fairly well', and 'very well'). As a logical consequence of the content of the name generating question used in this study, we may assume that respondents know their network members rather well, such that we can speak of triadic closure if two of one's friends know each other fairly well, or very well (cf. Mollenhorst et al. 2011). And as a consequence, for each unique pair of friends in one's network, the variable 'brokerage' indicates 
whether or not these two friends do not know each other at all or do not know each other very well. ${ }^{7}$

In the final analyses (see Tables 1,2), the variable 'proportion open triads (=brokerage)' is a variable that presents the number of triads in which the respondent is in a brokerage position (i.e., we count the number of open triads in the network), divided by the total number of triads in the respondent's network. Similarly, we constructed the variables for the different ethnic configurations of network triads, as presented in Fig. 1.

\subsubsection{Control Variables}

When analyzing the effects of ethnic brokerage on psychological well-being, we take into account a number of relevant sociodemographic characteristics and physical health indicators of the respondent. Most importantly, we determine the effect of the ethnic background of the respondents themselves. As discussed in Sect. 4, we expect that ethnic brokerage is more important to immigrants than to natives. For each respondent's ethnic background, we use the variable that distinguishes the three different sample strata: native Swedes, first- and second-generation immigrants from former Yugoslavia, and first- and second-generation immigrants from Iran (see Sect. 5.1). We also use a dummy-coded variable to check for differences between first- and second-generation immigrants. Next, we control for whether the respondent is married or has a boy- or girlfriend $(0=$ no, $1=$ yes $)$ as well as for each respondent's sex $(0=$ male, $1=$ female $)$, because our previous study (Mollenhorst et al. 2013) indicated that ethnic brokerage is more likely for women than for men. Other previous research suggests that the effects of social support on well-being are stronger in highly stressful times than in the absence of stress, e.g., higher levels of stress may be caused by a serious illness (e.g., Komproe et al. 1997; Penninx et al. 1998), but may also be present among immigrants who perceive discrimination (Jasinskaja-Lahti et al. 2006). Unfortunately, our dataset lacks information on perceived level of discrimination, but in order to determine whether the association between network characteristics and psychological well-being is affected by physical well-being (Ha and Kim 2012; Okun et al. 1984), we also control for four physical health indicators, based on the questions whether or not the respondents were slightly or much troubled by headaches/ migraine, stomach aches, back or neck pains, and/or asthma during the past 12 months.

In addition, due to the phrasing of the name generating question that was used in the survey, many respondents named (four or) five network members. The likelihood of triadic closure, however, may well be dependent on how close the respondent is connected to his/ her friends. ${ }^{8}$ We therefore control for the average quality of the relationships between the respondent and her/his friends (measured with a five-category Likert-scale response scheme: $1=$ not at all good; 5 = very good).

\footnotetext{
7 By looking at triads in personal networks, we neglect the possibility that a fourth actor also bridges the gap between the two unconnected actors (and consequently between groups).

${ }^{8}$ Compare one respondent who named 5 friends with whom she/he is very close, with another respondent who named 5 friends, having a very close relationship with two of them and a less close relationship with the other 3 friends. It is likely that the number of open triads in the latter network is larger.
} 


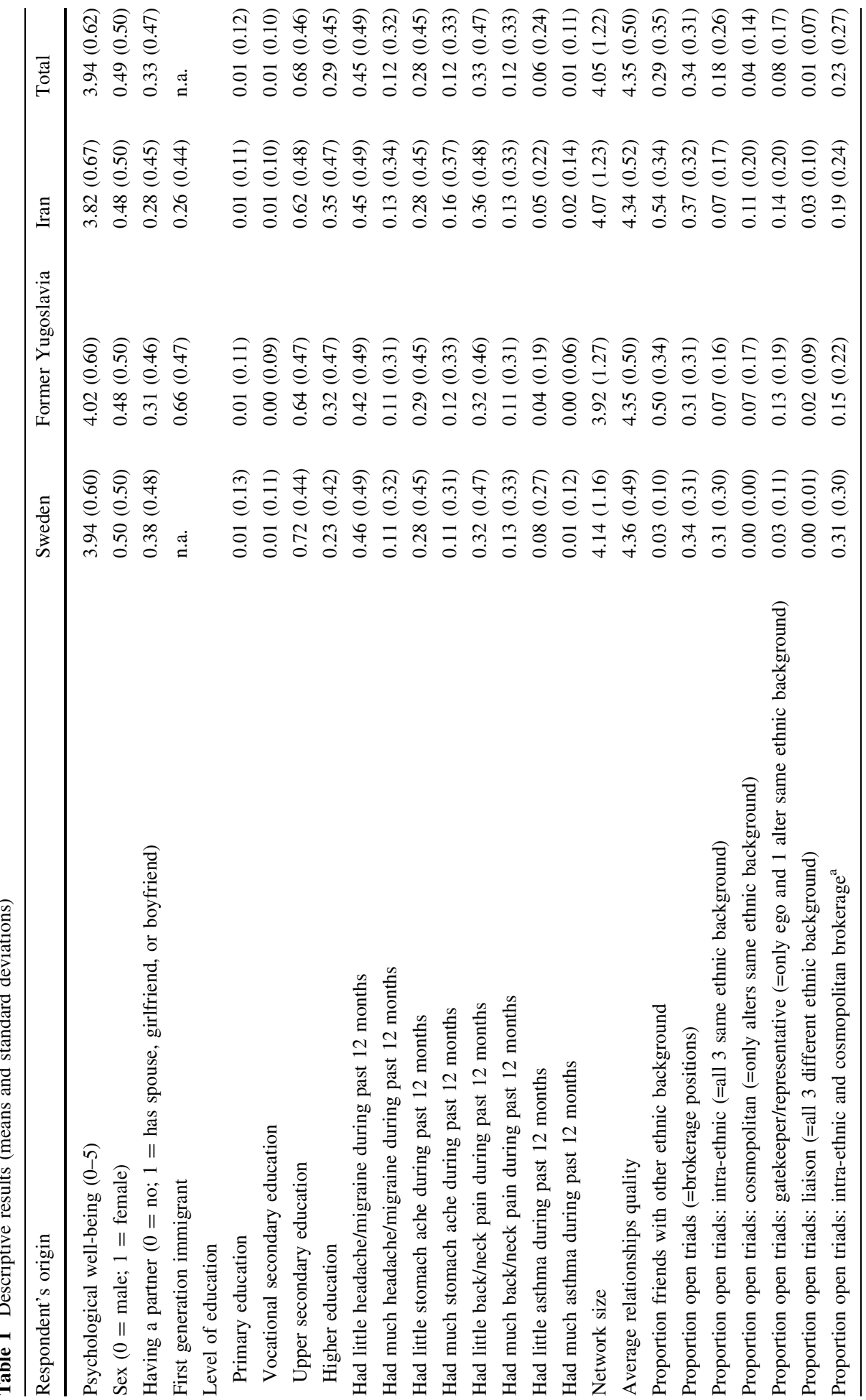




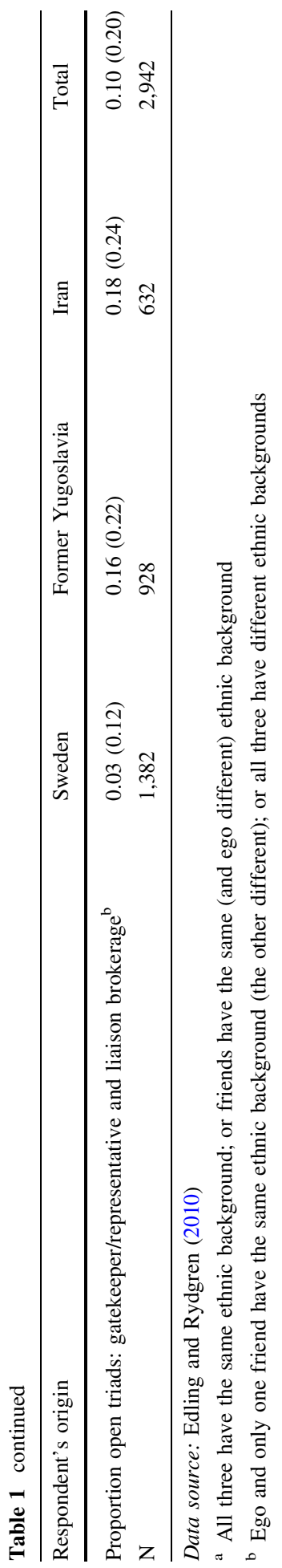




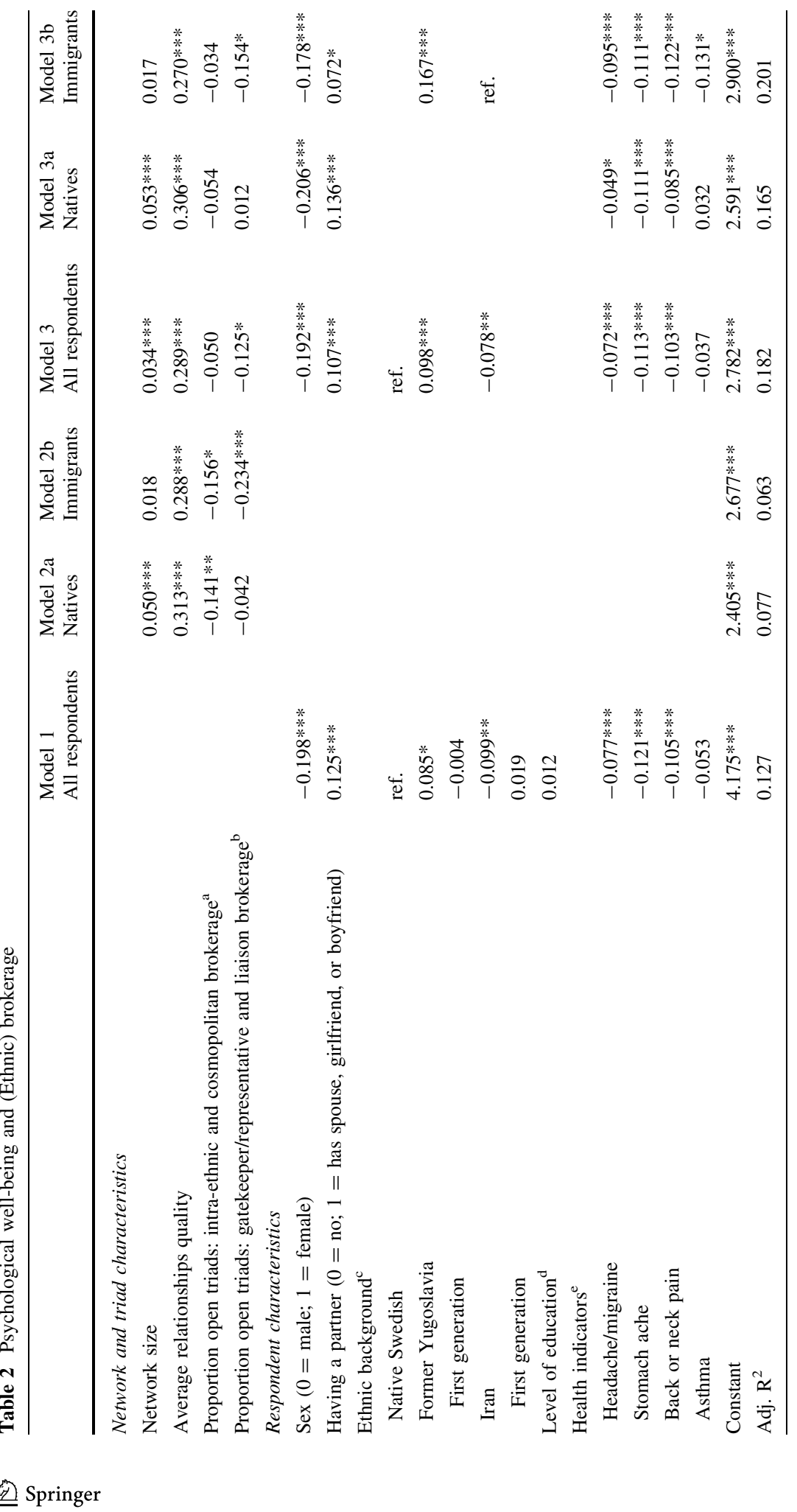




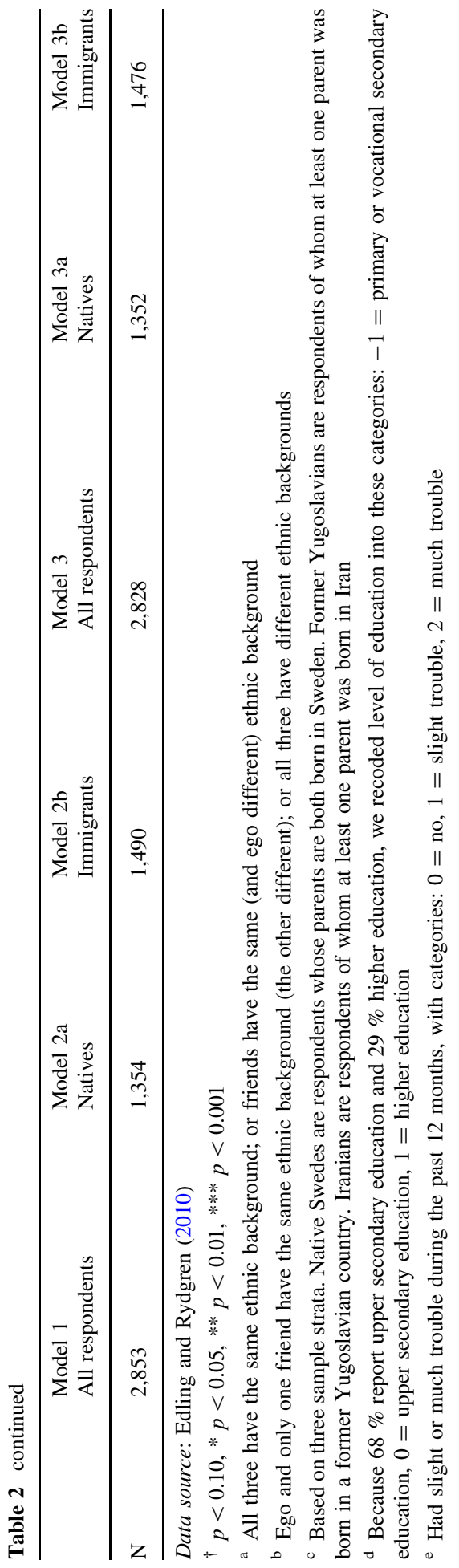




\section{Results}

Table 1 presents descriptive statistics on the dependent and independent variables that are used in this study. This table shows that first- and second-generation immigrants from former Yugoslavia on average report higher levels of psychological well-being, while immigrants from Iran on average score lower on psychological well-being than native Swedes. Bivariate tests show that-although the differences are not very large-these differences are statistically significant. The other descriptive statistics do not show very distinctive results for natives and immigrants and/or are in line with the findings as previously presented and discussed in Mollenhorst et al. (2013) and partly summarized in Sect. 3.2.

In Table 2, we present results from logistic regression analyses on how psychological well-being is associated with individual sociodemographic and physical health indicators, and with the ethnic composition and structure of friendship networks. The selection of these models is based on various additional models that are presented in Appendixes 2 and 3. We specifically note that based on these additional models, we decided to combine the initial four variables on the ethnic composition and the structure of network triads into two variables. We combined the proportion of open triads that consist of the respondent and two friends who all have the same ethnic background (coordinator or intra-ethnic brokerage), and the proportion of open triads that consist of two friends who have the same ethnic background and a respondent who has a different ethnic background (cosmopolitan brokerage) into one variable 'proportion open triads: intra-ethnic and cosmopolitan'. Likewise, we combine the proportion of open triads that consist of the respondent, one friend with the same ethnic background as the respondent, and one friend of a different ethnic background (gatekeeper/representative brokerage), and the proportion of open triads that consist of the respondent and two friends who all have different ethnic backgrounds (liaison brokerage) into one variable 'proportion open triads: gatekeeper/representative and liaison'. We did so because the latter variable now measures what we call 'interethnic brokerage', for which we expected that it would affect well-being over and above the effect of merely being in brokerage positions.

Model 1 shows how psychological well-being is associated with sociodemographic respondent characteristics and four indicators for physical health. This model indicates that overall, compared to native Swedes, immigrants of a former Yugoslavian background report higher levels of psychological well-being, while immigrants from Iran report lower levels of psychological well-being. Whether they are first- or second-generation immigrants does not make a significant difference in this respect (cf. Harker 2001). Men and those with a romantic partner (i.e., married or with a girlfriend or boyfriend) also report higher levels of well-being than women and those without a romantic partner. Moreover, we see that physical health is strongly related to psychological well-being: having experienced trouble from headaches or migraines, stomach aches and/or back or neck pains during the past 12 months, is negatively associated with psychological well-being (cf. Ha and Kim 2012; Okun et al. 1984).

In Models 2a and 2b and in Models 3a and 3b, we show results for native Swedes and for immigrants separately, because we expect that occupying an interethnic brokerage position in a friendship network has greater consequences for immigrants than for native Swedes: it is more likely that immigrants feel pressure to behave in accordance with the norms and values of their native friends than that natives feel obliged to behave in accordance to the norms and values of their friends of a foreign background. Models 2a and $2 \mathrm{~b}$ indicate that for both natives and immigrants, a higher average relationship quality 
between the respondent and her/his friends is positively associated with well-being, while a positive association between network size and well-being was only found for native Swedes.

Regarding the ethnic composition of friendship networks and the extent to which network triads are closed or open (i.e., brokerage positions), we first estimated the association between psychological well-being and the proportion of interethnic friendships in the networks of the respondent (Model 1a and 1b in Appendix 3), and next the association between psychological well-being and the proportion of open triads (brokerage positions) in friendship networks (Model 2a and 2b in Appendix 3). These results indicate that the proportion friends of another ethnic background does not by itself affect psychological well-being, while higher proportions of open triads is in general associated with lower levels of well-being. Model $2 \mathrm{~b}$ of Table 2, however, indicates an interaction effect between ethnic network composition and network structure: the higher the proportion of inter-ethnic brokerage positions (i.e., gatekeeper/representative and liaison brokerage) in the networks of immigrants, the lower their level of psychological well-being. Next, although the effects are smaller, we see that a higher proportion of intra-ethnic brokerage positions and/or 'cosmopolitan' brokerage positions (i.e., both friends have the same ethnic background, which is different from the focal actor's ethnic background) is associated with lower levels of psychological well-being. This latter finding applies to natives and immigrants.

Finally, in Models 3, 3a and 3b of Table 2, we show the extent to which the association between brokerage positions and psychological well-being is stable after controlling for sociodemographic respondent characteristics and physical health indicators. These models show that the positive association between network size (for natives) and well-being and the positive association between average relationship quality (for natives and immigrants) and well-being are robust. In fact, the beta coefficients in our models (not presented) reveal that of all independent variables included, relationship quality adds most to the prediction of psychological well-being.

The association between psychological well-being and the ethnic composition and structure of friendship networks, however, is affected by the other variables in Models $3 \mathrm{a}$ and $3 \mathrm{~b}$. Whereas the association between psychological well-being and the proportion of intra-ethnic and cosmopolitan brokerage was significant in Models $2 \mathrm{a}$ and $2 \mathrm{~b}$, we find no significant effects in Models 3a and 3b. Additional analyses (not presented) reveal that this is because Models 3a and 3b include the respondents' sex, while females have relatively more open triads in their friendship networks than men (see also Mollenhorst et al. 2013). For immigrants, the association between psychological well-being and interethnic brokerage in friendship networks, however, remains statistically significant: The more interethnic brokerage positions (gatekeeper/representative or liaison) they have in their friendship networks, the lower their psychological well-being.

Regarding the control variables, we see that the association between psychological wellbeing and the respondent's sex is not different among natives and immigrants. The association between having a romantic partner and psychological well-being, however, is stronger for natives than for immigrants, whereas the association between psychological well-being and physical health is somewhat stronger for immigrants than for natives. Finally, we observe that the coefficient for immigrants of a Yugoslavian background is substantial and highly significant. This indicates that-while taking into account differences in socio-demographic characteristics, physical health, ethnic network composition, and friendship network structure-immigrants from former Yugoslavia report higher levels of psychological well-being than immigrants from Iran. 


\section{Conclusions and Discussion}

We examined the association between ethnic brokerage and individuals' psychological well-being for two major reasons. First, we expected that individual psychological wellbeing would be more strongly associated with ethnic brokerage than with merely having interethnic personal relationships or with having a multi-ethnic network. Second, we expected that the consequences of network brokerage are especially salient and important if brokerage occurs between two distinct social groups. Brokering between two ethnic groups means that two of the focal actors' contacts have a different ethnic background and are not mutually connected, which may indicate salient and substantial differences between the norms, values, and corresponding behaviors between both ethnic groups.

Our results support these arguments. We show that the larger the proportion of interethnic open triads (=interethnic brokerage positions) in an immigrant's friendship network, the lower he or she scores on psychological well-being. The sheer proportion of co-ethnic and/or interethnic friendships is not significantly associated with one's score on psychological well-being. The sheer proportion of open triads (=inter- and intra-ethnic brokerage opportunities) is negatively associated with psychological well-being. If we control for individual sociodemographic characteristics and some self-reported health indicators, the negative association between psychological well-being and the proportion of open triads is stronger for interethnic open triads than for intra-ethnic triads, and in fact only applies to immigrants. This latter finding may partly be a result of the fact that interethnic open triads are much more prevalent in networks of immigrants than in networks of native Swedes. In other words, intra-ethnic brokerage is the typical brokerage configuration for native Swedes and interethnic brokerage is the typical brokerage configuration for immigrants (Mollenhorst et al. 2013).

Regarding the positive or negative consequences of being in an interethnic brokerage position on psychological well-being, we formulated hypotheses based on two opposing perspectives. Our finding that interethnic brokerage is negatively associated with psychological well-being supports our first hypothesis, which implies that the different norms, values, and corresponding behaviors that prevail in different ethnic groups to which the ethnic broker is connected may result in internal and external conflicts, to feelings that one is not fully accepted by any of these groups, and ultimately to a lower level of psychological well-being (cf. Krackhardt 1999; Pescosolido and Rubin 2000). This finding also implies that we do not find support for the argument that performing multiple roles would produce ego-gratification or strengthen and enrich one's personality (cf. Sieber 1974).

Compared to native Swedes, immigrants from former Yugoslavian countries scored higher on psychological well-being, while immigrants from Iran scored lower on psychological well-being (cf. Harker 2001). This could hardly be explained by the ethnic composition and/or structure of their friendship networks. We found that interethnic brokerage positions slightly depress the generally higher level of psychological well-being of former Yugoslavians, but explain little of the lower level of psychological well-being of Iranians.

Furthermore, some interesting results are found with regard to our control variables. Female respondents scored lower on psychological well-being than men, but we find that this cannot be explained by the fact that they are more often in interethnic brokerage positions (i.e., have more interethnic open triads in their friendship networks). In a previous paper (Mollenhorst et al. 2013), we showed that, compared to men, friendship networks of women contain more open triads, and that immigrant women are especially likely to be in interethnic brokerage positions. Considering that interethnic brokerage is negatively associated with psychological well-being of immigrants, this may also result in lower psychological well-being among immigrant women. In this paper, however, we show 
that (immigrant) women indeed score lower on psychological well-being, but that this negative association is hardly explained by their larger number of open interethnic friendship triads (i.e., the coefficient for females is robust through all models in Table 2). Physical health, in terms of headaches, stomach aches, back or neck pains, and/or asthma, is also substantially associated with psychological health (cf. Ha and Kim 2012; Okun et al. 1984). Altogether, these associations turn out to be rather robust, as is the association between interethnic (i.e., gatekeeper/representative or liaison) brokerage and psychological well-being of immigrants.

To conclude, our research indicates an interaction effect between the structure and the ethnic composition of friendship networks on individual's psychological well-being. Network structure, in terms of open versus closed triads, is significantly associated with psychological well-being, while the ethnic composition of friendship networks in itself is not significantly associated with psychological well-being. The negative association between an open network structure (i.e. open friendship triads) and psychological well-being, however, is stronger for interethnic friendship networks (triads) and predominantly applies to immigrants. This statistically significant association between interethnic brokerage and psychological well-being, although analyzed cross-sectionally, supports the idea that there are consequences to interethnic brokerage in personal networks for individual outcomes.

The association between psychological well-being and ethnic brokerage in these networks of strong ties turned out to be negative. Indeed, brokerage opportunities may occur more often in networks of weaker relationships, but the negative effect of interethnic brokerage may be more relevant and salient in friendship networks, because friends generally affect one's norms, values, and corresponding behaviors (and if these differ between the ethnic groups to which one is connected, one's psychological well-being as well) to a greater extent than do more superficial ties. Different consequences then may be found when examining more superficial ties and/or when addressing more 'instrumental' outcome variables, such as young immigrants' performance at school or their success in the labor market.

Acknowledgments This study is part of the research project "Individual Life Chances in Social ContextA Longitudinal Multi-Methods Perspective on Social Constraints and Opportunities", which is supported by a European Research Council (ERC) Starting Grant to Jens Rydgren as principal investigator (grant no. 263422). An earlier version of this paper was presented at the 10th Conference on Applications of Social Network Analysis at the University of Zürich, Switzerland (August, 2013).

\section{Appendix 1}

See Table 3.

Table 3 Ethnic and Interethnic Friendships (frequencies and percentages per stratum)

\begin{tabular}{llllllr}
\hline Respondent's origin & \multicolumn{2}{l}{ Friend's ethnic background } & & Total \\
\cline { 2 - 6 } & Sweden & Former Yugoslavia & Middle East & Other & Missing & \\
\hline Sweden & 5,473 & 29 & 14 & 167 & 44 & 5,726 \\
& 95.59 & 0.48 & 0.22 & 2.98 & 0.70 & 100 \\
Former Yugoslavia & 2,336 & 831 & 94 & 235 & 116 & 3,642 \\
& 63.78 & 23.59 & 2.50 & 6.88 & 3.22 & 100 \\
Iran & 1,995 & 63 & 308 & 161 & 47 & 2,574 \\
& 75.54 & 2.53 & 12.86 & 6.30 & 1.74 & 100 \\
\hline
\end{tabular}

Data source Edling and Rydgren (2010) 


\section{Appendix 2}

See Table 4.

Table 4 Psychological Well-being and Respondent Characteristics

\begin{tabular}{|c|c|c|c|}
\hline & $\begin{array}{l}\text { Model } 1 \\
\text { All } \\
\text { respondents }\end{array}$ & $\begin{array}{l}\text { Model } 2 \\
\text { All } \\
\text { respondents }\end{array}$ & $\begin{array}{l}\text { Model } 3 \\
\text { All } \\
\text { respondents }\end{array}$ \\
\hline \multicolumn{4}{|l|}{ Respondent characteristics } \\
\hline $\operatorname{Sex}(0=$ male $; 1=$ female $)$ & $-0.305^{* * *}$ & & $-0.198 * * *$ \\
\hline $\begin{array}{l}\text { Having a partner }(0=\text { no; } 1=\text { has spouse, girlfriend, or } \\
\text { boyfriend) }\end{array}$ & $0.106 * * *$ & & $0.125 * * *$ \\
\hline \multicolumn{4}{|l|}{ Ethnic background $^{\mathrm{a}}$} \\
\hline Native Swedish & ref. & & ref. \\
\hline Former Yugoslavia & $0.091^{*}$ & & $0.085^{*}$ \\
\hline First generation & -0.009 & & -0.004 \\
\hline Iran & $-0.122 * * *$ & & $-0.099 * *$ \\
\hline First generation & 0.028 & & 0.019 \\
\hline Level of education ${ }^{\mathrm{b}}$ & 0.028 & & 0.012 \\
\hline \multicolumn{4}{|l|}{ Health indicators ${ }^{\mathrm{c}}$} \\
\hline Headache/migraine & & $-0.089 * * *$ & $-0.077 * * *$ \\
\hline Stomach ache & & $-0.151 * * *$ & $-0.121 * * *$ \\
\hline Back or neck pain & & $-0.124 * * *$ & $-0.105^{* * *}$ \\
\hline Asthma & & $-0.065^{\dagger}$ & -0.053 \\
\hline Constant & $4.046 * * *$ & $4.167 * * *$ & $4.175^{* * *}$ \\
\hline Adj. $R^{2}$ & 0.074 & 0.089 & 0.127 \\
\hline $\mathrm{N}$ & 2,868 & 2,856 & 2,853 \\
\hline
\end{tabular}

Data source: Edling and Rydgren (2010)

${ }^{\dagger} p<0.10, * p<0.05$, ** $p<0.01$, *** $p<0.001$

a Based on three sample strata. Native Swedes are respondents whose parents are both born in Sweden. Former Yugoslavians are respondents of whom at least one parent was born in a former Yugoslavian country. Iranians are respondents of whom at least one parent was born in Iran

b Because $68 \%$ report upper secondary education and $29 \%$ higher education, we recoded level of education into these categories: $-1=$ primary or vocational secondary education, $0=$ upper secondary education, 1 = higher education

${ }^{c}$ Had slight or much trouble during the past 12 months, with categories: $0=$ no, $1=$ slight trouble, $2=$ much trouble

\section{Appendix 3}

See Table 5. 


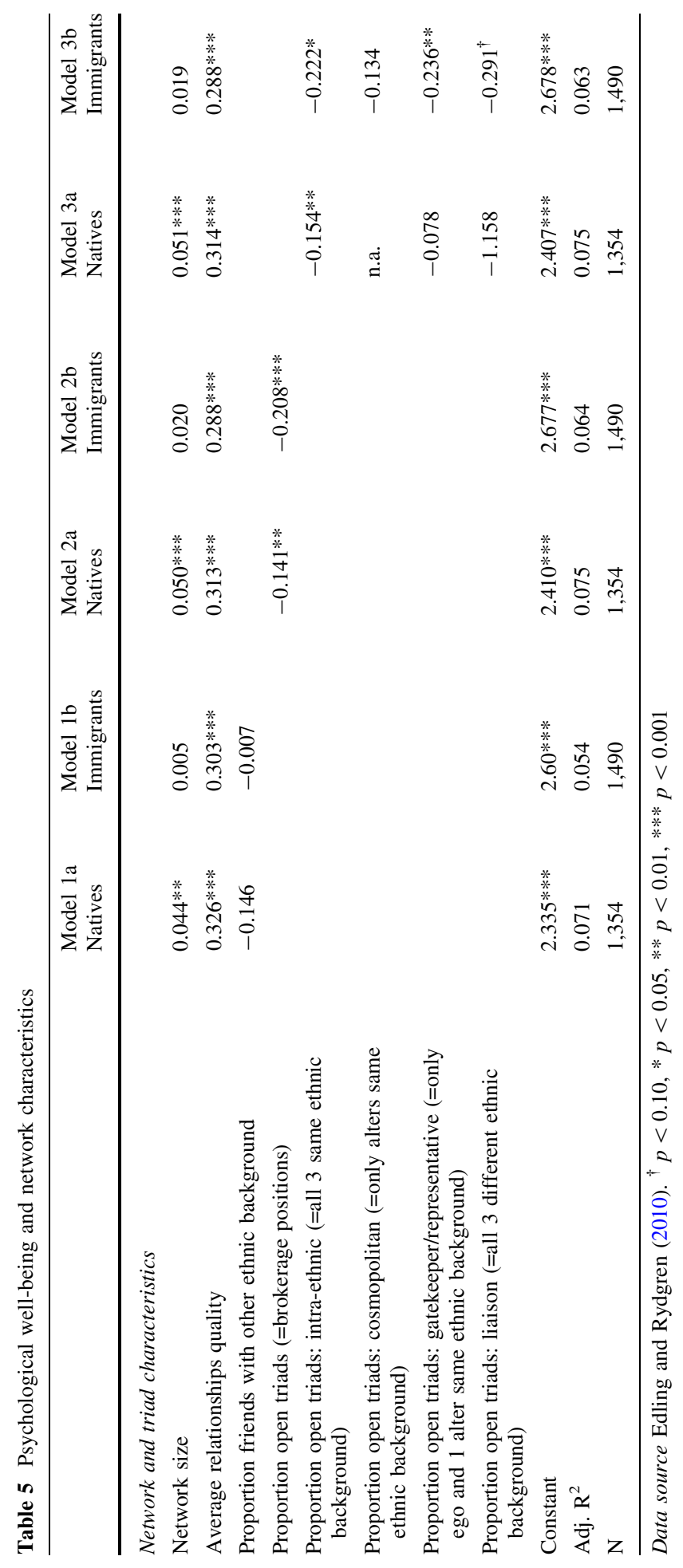




\section{References}

Bankston, C. L., \& Zhou, M. (2002). Being well vs. doing well. Self-esteem and school performance among immigrant and nonimmigrant racial and ethnic groups. International Migration Review, 36(2), 389-415.

Bian, Y. (1997). Bringing strong ties back in: Indirect ties, network bridges, and job searches in China. American Sociological Review, 62, 366-385.

Brännström, L. (2008). Making their mark: The effects of neighbourhood and upper secondary school on educational achievement. European Sociological Review, 24, 463-478.

Burt, R. S. (1992). Structural holes: The structure of competition. Cambridge, MA: Harvard University Press.

Chiswick, B. R., \& Miller, P. W. (1996). Ethnic networks and language proficiency among immigrants. Journal of Population Economics, 9, 19-35.

Cohen, S., \& Wills, T. A. (1985). Stress, social support, and the buffering hypothesis. Psychological Bulletin, 98, 310-357.

De Miguel Luken, V., \& Tranmer, M. (2010). Personal support networks of immigrants to Spain: A multilevel analysis. Social Networks, 32, 253-262.

Edling, C., \& Rydgren, J. (2010). Social capital and labor market integration: A cohort study-Data and codebook. Stockholm: Stockholm University.

Edling, C., \& Rydgren, J. (2012). Neighborhood and friendship composition in adolescence. Sage Open, 2(4), 1. doi:10.1177/2158244012466249.

Finch, J. F., Okun, M. A., Barrera, M, Jr, Zautra, A. J., \& Reich, J. W. (1989). Positive and negative social ties among older adults: Measurement models and the prediction of psychological distress and wellbeing. American Journal of Community Psychology, 17(5), 585-605.

Fong, E., \& Isajiw, W. W. (2000). Determinants of friendship choices in multiethnic society. Sociological Forum, 15, 249-269.

Goode, W. J. (1960). A theory of role strain. American Sociological Review, 25, 483-496.

Gould, R. V., \& Fernandez, R. M. (1989). Structures of mediation: a formal approach to brokerage in transaction networks. American Sociological Review, 19, 89-126.

Granovetter, M. S. (1974). Getting a job: A study of contacts and careers. Cambridge, MA: Harvard University Press.

Greenman, E., \& Xie, Y. (2008). Is assimilation theory dead? The effect of assimilation on adolescent wellbeing. Social Science Research, 37, 109-137.

Ha, S. E., \& Kim, S. (2012). Personality and subjective well-being: Evidence from South Korea. Social Indicators Research, 111(1), 341-359.

Hällsten, M., Edling, C., \& Rydgren, J. (2012). Acculturation Identity, Social Context and Individual Outcomes: Evidence for Individuals of Iranian and Yugoslavian Origins in Sweden. Paper presented at ECSR/Equalsoc Conference. Aula Magna/Stockholm University, Sweden, September 2012.

Harker, K. (2001). Immigrant generation, assimilation and adolescent psychological well-being. Social Forces, 79(3), 969-1004.

Jasinskaja-Lahti, I., Liebkind, K., Jaakkola, M., \& Reuter, A. (2006). Perceived discrimination, social support networks, and psychological well-being among three immigrant groups. Journal of crosscultural psychology, 37(3), 293-311.

Kalmijn, M. (1998). Intermarriage and homogamy: Causes, patterns, trends. Annual Review of Sociology, 24, 395-421.

Kanas, A., \& Van Tubergen, F. (2009). The impact of origin and host country schooling on the economic performance of immigrants. Social Forces, 88, 893-916.

Kao, G., \& Joyner, K. (2004). Do race and ethnicity matter among friends? Activities among interracial, interethnic, and intraethnic adolescent friends. The Sociological Quarterly, 45, 557-573.

Komproe, I. H., Rijken, M., Ros, W. J. G., Winnubst, J. A. M., \& Hart, H. 't (1997). Available support and perceived support: Different support under stressful circumstances. Journal of Social and Personal Relationships, 14(1), 59-77.

Krackhardt, D. (1999). The ties that torture: Simmelian tie analyses in organizations. Research in the Sociology of Organizations, 16, 183-210.

Liebkind, K., \& Jasinskaja-Lahti, I. (2000). Acculturation and psychological well-being among immigrant adolescents in Finland: A comparative study of adolescents from different cultural backgrounds. Journal of Adolescent Research, 15, 446-469.

Marks, S. R. (1977). Multiple roles and role strain: Some notes on human energy, time and commitment. American Sociological Review, 42(6), 921-936. 
Marsden, P. V. (1982). Brokerage behavior in restricted exchange networks. In P. V. Marsden \& N. Lin (Eds.), Social structure and network analysis (pp. 201-218). Beverly Hills: Sage.

Martinovic, B. (2013). The inter-ethnic contacts of immigrants and natives in the Netherlands: A two-sided perspective. Journal of Ethnic and Migration Studies, 39(1), 69-85.

Martinovic, B., Van Tubergen, F., \& Maas, I. (2009). Dynamics of interethnic contact: A panel study of immigrants in the Netherlands. European Sociological Review, 25(3), 303-318.

Merton, R. K. (1957). Social theory and social structure. Glencoe, IL: The Free Press.

Mollenhorst, G., Edling, C., \& Rydgren, J. (2013). Ethnic brokerage in friendship networks. Paper presented at international sunbelt social network conference XXXIII. Hamburg, Germany, May 2013.

Mollenhorst, G., Rydgren, J., \& Edling, C. (2012). Triadic closure in friendship networks: Disentangling the effects of social distance, ethnic similarity and shared contexts. Paper presented at international sunbelt social network conference XXXII. Redondo Beach, CA, March 2012.

Mollenhorst, G., Völker, B., \& Flap, H. (2011). Shared contexts and triadic closure in core discussion networks. Social Networks, 33, 292-302.

Musterd, S. (2005). Social and ethnic segregation in Europe: Levels, causes, and effects. Journal of Urban Affairs, 27, 331-348.

Obstfeld, D. (2005). Social networks, the 'tertius iungens' orientation, and involvement in innovation. Adminstrative Science Quarterly, 50, 100-130.

Okun, M. A., Stock, W. A., Haring, M. J., \& Witter, R. A. (1984). Health and subjective well-being: A metaanalysis. International Journal of Aging and Human Development, 19(2), 111-132.

Penninx, B. W. J. H., Van Tilburg, T., Boeke, A. J. P., Deeg, D. J. H., Kriegsman, D. M. W., \& Van Eijk, J. T. M. (1998). Effects of social support and personal coping resources on depressive symptoms: Different for various chronic diseases? Health Psychology, 17, 551-558.

Pescosolido, B. A., \& Rubin, B. A. (2000). The web of group affiliations revisited: Social life, postmodernism, and sociology. American Sociological Review, 65(1), 52-76.

Phinney, J. S., Horenczyk, G., Liebkind, K., \& Vedder, P. (2001). Ethnic identity, immigration and wellbeing: An interactional perspective. Journal of Social Issues, 57(3), 493-510.

Pierce, G. R., Sarason, B. R., \& Sarason, I. G. (1996). Handbook of social support and the family. New York: Plenum.

Podolny, J. M., \& Baron, J. N. (1997). Social networks and mobility. American Sociological Review, 62, 673-693.

Rook, K. S. (1984). The negative side of social interaction: Impact on psychological well-being. Journal of Personality and Social Psychology, 46(5), 1097-1108.

Sieber, S. D. (1974). Toward a theory of role accumulation. American Sociological Review, 39(4), 567-578.

Simmel, G. (1908[1950]). The stranger. In K. H. Wolff (Transl. Ed.) The Sociology of Georg Simmel (pp. 402-408). New York: Free Press.

Simmel, G. (1922[1955]). The web of group-affiliations. In K. H. Wolff \& R. Bendix (Transl. Ed.) Conflict and the web of group-affiliations (pp. 125-195). New York: Free Press.

Simmel, G. (1950). The triad. In K. H. Wolff (Transl. Ed.) The sociology of Georg Simmel (pp. 145-169). New York: Free Press.

Stovel, K., \& Shaw, L. (2012). Brokerage. Annual Review of Sociology, 38, 139-158.

Thoits, P. A. (1983). Multiple identities and psychological well-being: A reformulation and test of the social isolation hypothesis. American Sociological Review, 48(2), 174-187.

Verkuyten, M., \& Nekuee, S. (1998). Subjective well-being, discrimination and cultural conflict: Iranians living in the Netherlands. Social Indicators Research, 47, 281-306.

Vervoort, M., \& Dagevos, J. (2011). The social integration of ethnic minorities: An explanation of the trend in ethnic minorities' social contacts with natives in the Netherlands, 1998-2006. Journal of Ethnic and Migration Studies, 37(4), 619-635. 